\title{
Mechanical behavior and failure micromechanisms of hybrid 3D woven composites in tension
}

\author{
R. Muñoz , V. Martínez , F. Sket , C. González ，J. Llorca
}

\begin{abstract}
A B S T R A C T
The deformation and failure micromechanisms of a hybrid 3D woven composite were studied in tension. Plain and open-hole composite coupons were tested in tension until failure in the fill and warp directions, as well as fiber tows extracted from the dry fabric and impregnated with the matrix. The macroscopic evolution of damage in the composite coupons was assessed by means of periodic unloading-reloading (to obtain the elastic modulus and the residual strain), whereas the microscopic mechanism were established by means of X-ray computed microtomography. To this end, specimens were periodically removed from the mechanical testing machine and infiltrated with Znl-containing liquid to assess the main damage modes as a function of the applied strain. The experimental observations and the predictions of an isostrain model were used to understand the key factors controlling the elastic modulus, strength and notch sensitivity of hybrid 3D woven composites in tension. It was found that the full contribution of the glass fibers to the composite strength was not employed, due to the premature fracture of the carbon fibers, but their presence increased the fracture strain and the energy dissipated during fracture. Thus, hybridization of the 3D woven composite led to a notch-insensitive behavior as demonstrated by open-hole tests.
\end{abstract}

\section{Introduction}

Fiber-reinforced polymers stand out among the most successful structural materials due to the combination of low density, high stiffness and strength and reasonable damage tolerance and impact resistance. In addition, their performance can be optimized for specific applications by choosing the fiber type, volume fraction and orientation, stacking sequence, etc., normally within the framework of 2D laminates. However, more sophisticated strategies are available to further improve the composite behavior for specific applications. They include hybrid composites containing two or more fiber types and 3D fiber architectures.

Hybrid composites in which carbon fibers are used in combination with higher strain-to-failure fibers have consistently demonstrated better damage tolerance under impact, reduced notch-sensitivity and improved fracture toughness than their carbon-fiber counterparts [1-6]. Fiber architecture has an even stronger influence on the mechanical response [7]. The baseline materials for comparison are conventional multidirectional laminates manufactured from unidirectionally-reinforced pre-preg sheets. They show excellent in-plane properties due to the lack of crimping, but low delamination resistance under out-of-plane loads. This problem can be partially overcome with 2D fabrics, although the in-plane stiffness and strength are reduced, while non-crimp fabrics provide properties in between these fiber architectures.

More radical differences (and a much wider design space) is achieved when textile manufacturing techniques are applied to create 3D fiber preforms. The huge variety and the complexity of the 3D fiber architecture makes the prediction of mechanical properties of 3D composites a challenging task, as their deformation and failure mechanisms are very complex and can show large differences as a function of the loading conditions and of the 3D fiber preform. Early studies $[8,9]$ showed that 3D woven composites presented higher failure strains than conventional multiaxial laminates, together with lower notch sensitivity and higher work of fracture, Following this pioneer work, there were many papers available in the literature on the mechanical response of 3D composites, but detailed studies focussing on the comprehensive assessment of the dominant damage micromechanisms in different 3D fiber preforms have appeared recently. For instance, Gerlach et al. [10] studied the effect of the volume fraction of through-the-thickness binder on the in-plane and out-of-plane properties of 3D woven composites as a function of the strain rate. 
Bogdanovich et al. [11] and Ivanov et al. [12] carried out a comprehensive experimental analysis of the elastic constants and damage micromechanisms of 3D non-crimp orthogonal woven composites loaded in tension. They showed that non-crimp 3D orthogonal woven composites have significantly higher in-plane strengths, failure strains and damage initiation thresholds than the $2 \mathrm{D}$ woven laminated counterparts [12]. The effect of 3D reinforcement on delamination was studied by Pankow et al. [13], whereas Seltzer et al. [14] performed a detailed investigation on the damage mechanisms under low-velocity impact of various 3D orthogonal woven composites and highlighted the differences between those observed in 2D woven materials. This latter study demonstrated that state-of-the art 3D characterization techniques, such as Xray microtomography (XCT), are extremely useful to understand the initiation and progression of damage in these materials in which failure processes are inherently 3D.

While the analysis of the failure mechanisms in hybrid or 3D composites has been studied in the past, there are few comprehensive studies on this topic for hybrid 3D composites containing two or more fiber types [15]. This was the main goal of this investigation, which presents a detailed analysis of the failure micromechanisms in tension of a hybrid 3D orthogonal woven composite. The evolution of damage as a function of the applied strain was monitored by means of progressive reduction in stiffness and the increment of the residual strain as well as by XCT. The composite properties (stiffness, strength) were compared with predictions obtained from the actual properties of the fiber tows, which were measured independently. All this information provides a comprehensive picture of the effect of fiber hybridization, 3D fiber architecture, crimping and damage on the mechanical behavior in tension of hybrid 3D woven composites.

\section{Material}

A flat composite panel was manufactured by vacuum infusion of an epoxy-vinylester resin (Derakane 8084) into a hybrid 3D orthogonal woven composite. Both the dry perform and composite panel were provided by 3TEX, Inc. (Cary, North Carolina, USA) with the commercial name $\mathrm{p} 3 \mathrm{w}$-d00001-hx21. The preform was nonsymmetric and consisted of three warp $(0)$ and four fill (90) fiber layers stacked as a cross-ply laminate $\left[90_{c}, 0_{c}, 90_{c / s 2}, 0_{s 2}, 90_{s 2}, 0_{s 2}\right.$, $90_{s 2}$ ]. The schematic of the 3D fiber preform is shown in Fig. 1. The fibers in each layer were distributed in yarns rectangular in shape. The top four layers were made up of S2 glass fibers and the bottom 2 layers of AS4C carbon fibers. The hybrid layer (containing glass and carbon fibers) oriented in the fill direction was located between the glass and the carbon layers. Each tow of this layer contained both AS4C and S2 glass fibers, which were not intermingled but separated in two different zones of the tow (i.e. one half of the tow was formed by carbon fibers and the other half by glass fibers). It should also be noticed that every other tow was missing in the carbon layer oriented in the warp direction. In addition, the composite panel was reinforced in the through-thickness direction by z-yarn binders made up of ultra-high molecular weight polyethylene (PE) fiber (Dyneema SK75) that went from top to bottom layers in the warp direction. Note that consecutive $\mathrm{z}$-yarns were in antiphase.

The nominal thickness of the dry fabric was $3.02 \mathrm{~mm}$ and its areal density was $4.24 \mathrm{~kg} / \mathrm{m}^{2}$. The nominal thickness of the composite was $4.1 \mathrm{~mm}$, with an areal density of $6.44 \mathrm{~kg} / \mathrm{m}^{2}$. The overall fiber volume fraction in the composite was $47 \%$ and the porosity, as measured by XCT, was $11.6 \%$. The volume fraction of each type of fiber in each direction (warp or fill) is shown in Table 1. It was determined from the areal density of the individual plies and the fiber density, which were provided by the manufacturer. In

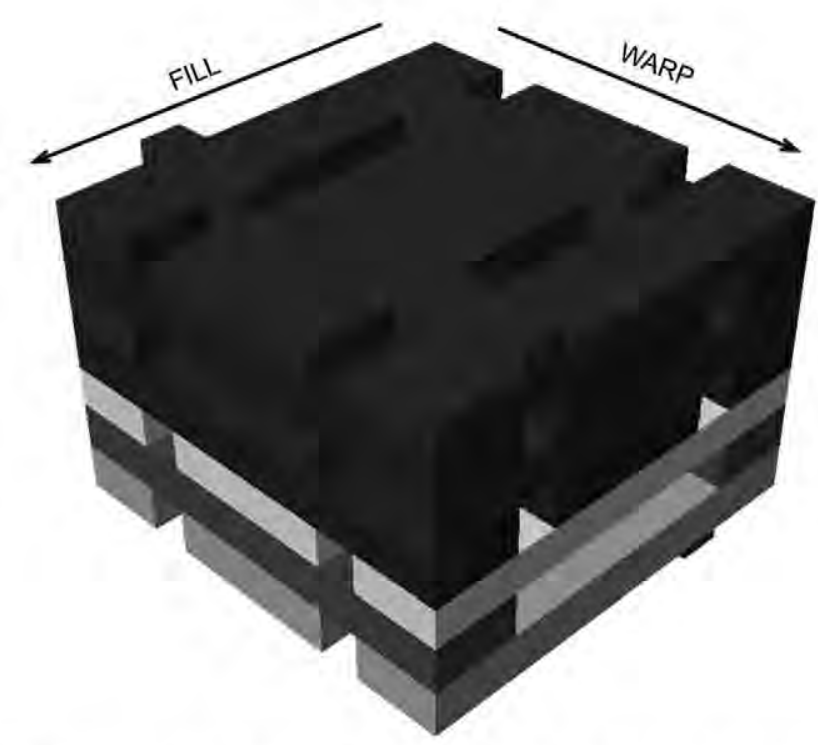

Fig. 1. Schematic of the unit cell of the hybrid 3D woven fiber preform. Carbon fiber bundles are shown in gray (dark gray for the warp direction and light gray for the fill), hybrid bundles in white and glass fiber bundles in red (dark red in the warp direction and light red in the fill direction). PE z-yarn binders in the warp direction are plotted in navy blue. (For interpretation of the references to colour in this figure legend, the reader is referred to the web version of this article.)

Table 1

Density $(\rho)$ and volume fraction of matrix and fibers as a function of fiber type and orientation within the hybrid composite.

\begin{tabular}{lllll}
\hline Material & $\rho\left(\mathrm{g} / \mathrm{cm}^{3}\right)$ & Warp $(\%)$ & Fill (\%) & Total $(\%)$ \\
\hline Glass S2 & 2.48 & 15.4 & 14.7 & 30.1 \\
Carbon AS4C & 1.78 & 4.3 & 10.7 & 15.0 \\
Polyethylene SK75 & 0.97 & 1.9 & - & 1.9 \\
Total fibers & & 21.6 & 25.4 & 47 \\
Matrix & 1.02 & & & 53 \\
\hline
\end{tabular}

addition, the matrix volume fraction was determined from the matrix density and the weight of the composite panel before and after infiltration and this is also given in Table 1.

\section{Experimental techniques}

\subsection{Mechanical characterization}

Rectangular specimens of $250 \times 25 \times 4.1 \mathrm{~mm}^{3}$ were machined from the plate with the longest dimension aligned in either the warp or fill direction for the mechanical tests. Glass tabs of $50 \mathrm{~mm}$ in length were glued to the specimens, leading to a free length of $150 \mathrm{~mm}$. They were tested in tension in an electromechanical universal testing machine (Instron 3384) following the recommendations of the ASTM Standard D3039 [16] and of the ASTM Standard D5766 [17] for rectangular coupons with a central hole of $4.1 \mathrm{~mm}$ and $11 \mathrm{~mm}$ in diameter. Tests were carried out under stroke control at $2 \mathrm{~mm} / \mathrm{min}$ and the load was continuously measured during the test with a load cell of $150 \mathrm{kN}$. Since composite is non-symmetric (and coupling between bending and extension might occur), the longitudinal strain was recorded on both faces of the specimen using an extensometer of $50 \mathrm{~mm}$ gage length on one face and digital image correlation (Vic2D) on the other. The strain reported with digital image correlation was that corresponding to a virtual extensometer, whose gage length was equal to that of the actual extensometer on the other side. Periodic unloadingreloading was carried out in one test in each direction (warp or fill) 
to estimate the stiffness degradation as a function the applied strain.

In addition to the composite specimens, the mechanical properties of the different fiber tows were also measured following the recommendations of the ASTM Standard D4018 [18]. To this end, individual tows of carbon, glass and PE were carefully extracted from the dry fabric to avoid damage. They were impregnated with Derakane 8084 epoxy-vinylester resin and cured at room temperature, following the instructions of the resin manufacturer, with a gelification time of $30 \mathrm{~min}$. The linear density of the fiber tows before and after impregnation was measured. Glass fiber tabs were glued to the impregnated tows, leading to a free length of $150 \mathrm{~mm}$. They were tested in tension until failure under stroke control at $5 \mathrm{~mm} / \mathrm{min}$. Load and strain were continuously recorded during the test, the latter with an extensometer.

Thermo-gravimetric analyses of the impregnated carbon and glass yarns were conducted in a TGA Q50 Thermal Analyser (TA Instruments). All experiments were carried out in air with a purge rate of $60 \mathrm{ml} / \mathrm{min}$ and a heating rate of $10^{\circ} \mathrm{C} / \mathrm{min}$ up to $1000^{\circ} \mathrm{C}$. The sample weight was approximately $10 \mathrm{mg}$ and $18 \mathrm{mg}$ for carbon and glass fiber tows, respectively. The fiber weight fractions were $64 \%$ and $69 \%$ for carbon and glass fibers, respectively, which led to fiber volume fractions of $50.5 \%$ and $48 \%$. This methodology could not be used to obtain the fiber volume fraction in the PE fiber yarns because of the low melting point of the fibers.

\subsection{Damage inspection}

The damage micromechanisms in the composite specimens tested in tension in the warp and fill directions were analyzed as a function of the applied strain by means of XCT. To this end, two coupons in each direction were deformed up to pre-defined strains. The tests were stopped and the specimens were immersed in a liquid for $2 \mathrm{~h}$ while holding the displacement constant to facilitate the penetration of the liquid into the cracks. The liquid was composed of $60 \mathrm{~g}$ of $\mathrm{ZnI}$ in $10 \mathrm{ml}$ of water, $10 \mathrm{ml}$ of ethanol and $10 \mathrm{ml}$ of Kodak Photo-Flo 200. The specimens were removed from the machine and inspected by XCT as detailed below. Previous investigations have demonstrated that the immersion in this liquid does not modify the damage mechanisms in composites [19].

XCT of the specimens was performed with a Nanotom 160NF (Phoenix) at $70-90 \mathrm{kV}$ and $120-180 \mathrm{~mA}$ using a tungsten target, 1800 radiographs were acquired for each tomogram with an exposure time of $1000 \mathrm{~ms}$. The 3D tomograms were reconstructed from the radiographs using an algorithm based on the filtered back-projection procedure for Feldkamp cone beam geometry. The reconstructed volumes presented a resolution of $13-15 \mu \mathrm{m} /$ voxel and were analyzed using the commercial software VGStudio Max. The contrast provided by the dye penetrant liquids enhances the crack detection capability of XCT in composite materials. It has been shown that cracks with an opening of the order of $5 \%$ the reconstructed voxel size (13-15 $\mu \mathrm{m}$ in this study) can be detected because the dye provide enough contrast to give a different gray level to the whole voxel. Thus cracks with openings around $1-2 \mu \mathrm{m}$ could be detected [20-22]. It is also important to mention that the immersion was performed with the samples under load, facilitating the liquid infiltration within the cracks. This methodology provides higher resolution than immersing the unloaded sample in the liquid. Emphasis was placed on the qualitative assessment of the main damage mechanism in each material as a function of applied strain rather than in the quantification of specific damage modes (delaminated surface, volume of cracked tows, fraction of broken fibers, etc.).

\section{Mechanical properties}

\subsection{Fiber tows}

Six tows were tested in tension until failure for each fiber type and the average stress in the fibers is plotted as a function of the applied strain in Fig. 2 for the carbon (AS4C), glass (S2) and polyethylene (SK75) fibers. The matrix contribution was neglected in the stress analysis and the average stress in the carbon and glass fibers was computed from the applied load $P$, the tow cross-section and the fiber volume fraction, as determined by the thermo-gravimetric analysis. In the case of the PE yarns, the average fiber stress was computed as $P \rho_{f} / \hat{y}_{y}$, where $\rho_{f}$ stands for the fiber density and $\lambda_{y}$ is the linear density of the dry yarn.

The carbon tows (Fig. 2a) presented a linear elastic behavior up to $0.5 \%$ strain. Beyond this point, three specimens showed a slight reduction in stiffness whereas two maintained the initial modulus until failure. One specimen presented evidence of damage (sudden stress drop) before final failure. All of them failed in a brittle fashion when the strain was in the range 1.2-1.9\%. Evidence of carbon stiffening was not found in these tests. The glass fiber tows (Fig. 2a) also presented a linear elastic behavior up to $1.6 \%$. The elastic modulus decreased with the applied strain beyond this point and damage prior to failure was observed in most of the yarns for applied strains in the range $2-3 \%$. This damage was due to the progressive failure of fibers within the yarn. Final fracture occurred in a brittle
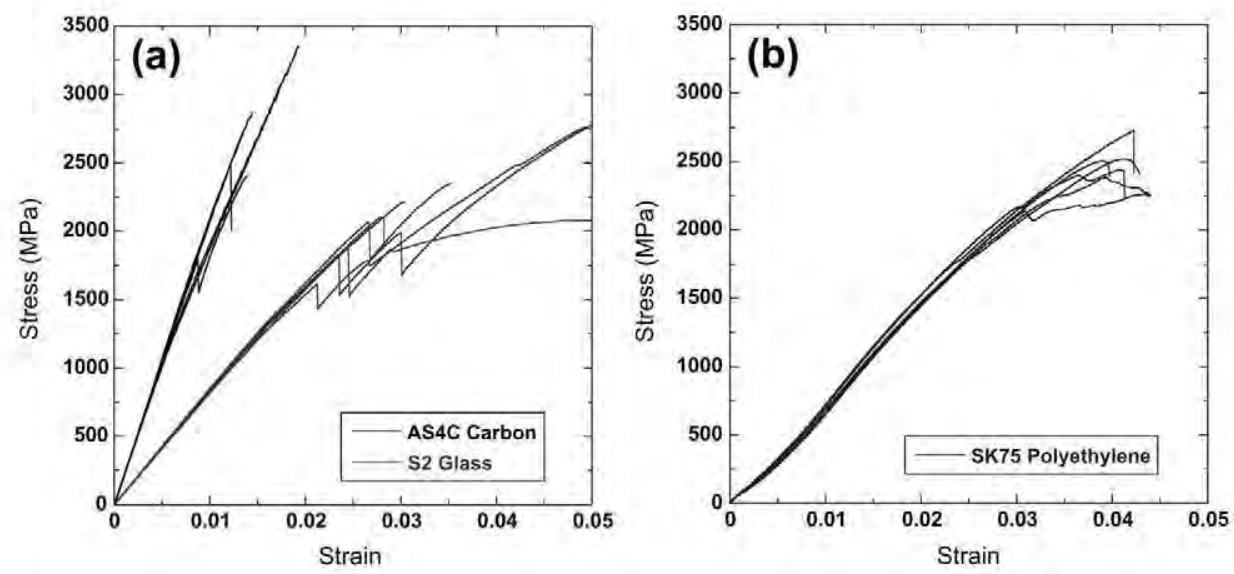

Fig. 2. Stress-strain curves of the fiber tows. (a) Carbon and glass fiber tows. (b) Polyethylene fiber yarns. (For interpretation of the references to colour in this figure legend, the reader is referred to the web version of this article.) 
fashion, as in the case of the carbon fiber tows, although at higher strains (in the range 3-5\%). The PE fiber yarns (Fig. 2b) showed a more ductile behavior and the stress-strain curves were non-linear in the whole range of deformation. The elastic modulus increased up to $1.0-1.5 \%$ strain and then decreased up to failure, which occurred at an applied strain in the range $4.0-4.3 \%$. It should be noted that the scatter in the stress-strain curves of the PE yarns was very small. The average elastic modulus, failure strain and tensile strength of the fiber tows, together with the corresponding standard deviations, are summarized in Table 2.

\subsection{Tensile properties of plain coupons}

Three tensile tests were carried out in the fill and warp directions and the corresponding stress-strain curves are plotted in Fig. 3a and b, respectively. The strains were measured by conven-

Table 2

Elastic modulus, tensile strength and fracture strain of the fibers within the fiber yarns.

\begin{tabular}{lccc}
\hline Fiber type & $\begin{array}{c}\text { Elastic } \\
\text { modulus } \\
(\mathrm{GPa})\end{array}$ & $\begin{array}{c}\text { Tensile } \\
\text { strength } \\
(\mathrm{GPa})\end{array}$ & $\begin{array}{c}\text { Failure strain } \\
(\%)\end{array}$ \\
\hline Glass S2 & $82 \pm 1$ & $2.4 \pm 0.3$ & $4.0 \pm 1.0$ \\
Carbon AS4C & $207 \pm 2$ & $2.8 \pm 0.4$ & $1.5 \pm 0.2$ \\
Polyethylene SK75 & $85 \pm 1$ & $2.5 \pm 0.2$ & $4.1 \pm 0.2$ \\
\hline
\end{tabular}

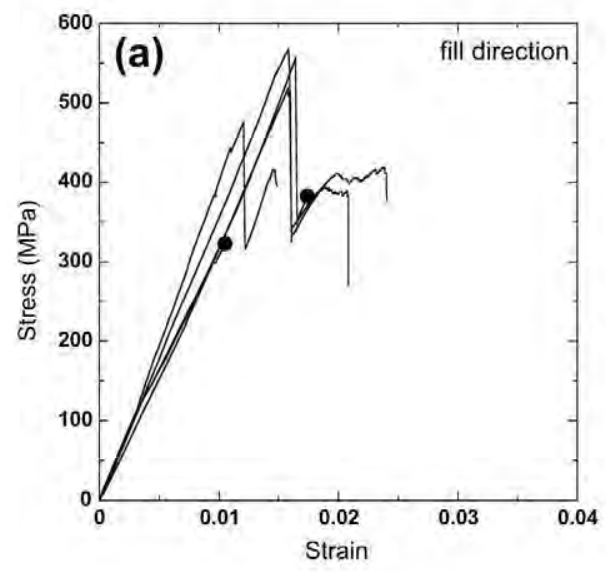

tional extensometry on the glass face of the coupon and by digital image correlation on the carbon face. They are plotted in Fig. $3 \mathrm{c}$ for two representative tests in the fill and warp direction. The differences in the strain between both faces were negligible, indicating that the extension-bending coupling induced by the asymmetry of the composite did not play a significant role in the tensile behavior at least until the fracture of the carbon fibers.

The stress-strain curves in the fill direction (Fig. 3a) presented a linear-elastic behavior up to a strain in the range $1.2-1.6 \%$, which is similar to the failure strain of the carbon fiber tows (Fig. 2a). There was a sudden drop in the load bearing capacity of the composite but the load increased slightly with further strain until catastrophic failure, which occurred at an applied strain below $2.5 \%$. The initial part of the stress-strain curve was also linear in the warp direction (Fig. 3b), but a slight non-linearity was detected before the load peak, which occurred when the applied strain was in the range $1.3-1.7 \%$, as in the fill direction. Nevertheless, the load bearing capacity of the composite increased with further straining and the maximum strength was attained for applied strains in the range $2.1-3.1 \%$, just before the coupon failed catastrophically. This failure strain is compatible with the development of damage in the glass fiber tows.

Thus, composite coupons loaded in tension along the fill and warp direction presented two peaks. The maximum strength along the fill direction was attained in the first peak and it was controlled by the fracture of the AS4C carbon fiber yarns. The maximum strength in the warp direction was attained in the second peak and it was controlled by the fracture of the $\mathrm{S} 2$ glass fiber tows. It

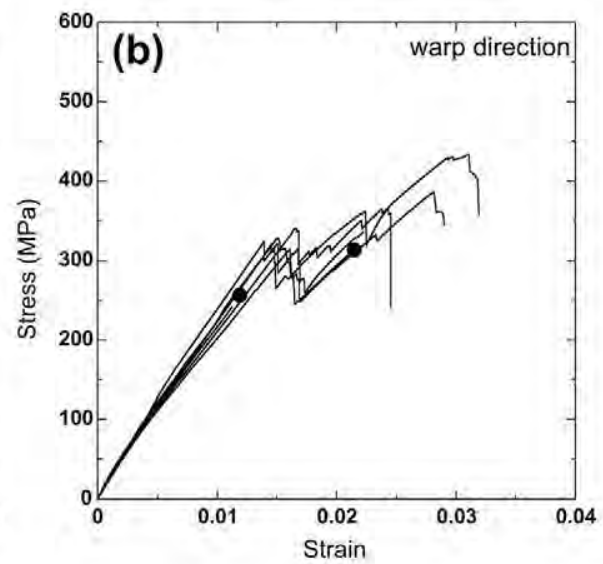

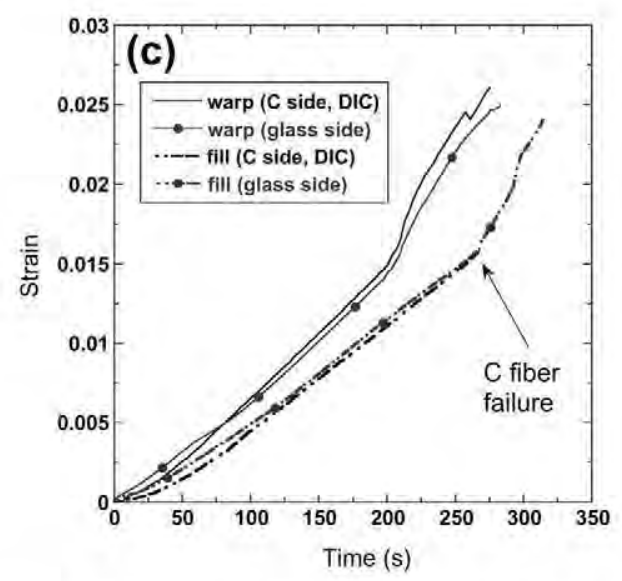

Fig. 3. Stress-strain curves of the plain composite coupons. (a) Fill direction. (b) Warp direction. The solid circles in the curves indicate the instants in which the test was stopped and the coupons were examined by means of XCT. (c) Tensile strains measured by conventional extensometry on the glass side and by digital image correlation on the carbon side for two representative tests in the fill and warp direction, respectively. (For interpretation of the references to colour in this figure legend, the reader is referred to the web version of this article.) 
should be noted that the main differences in the composite architecture between the fill and warp direction were the presence of an extra hybrid ply with the fibers oriented in the fill direction and that the PE z-yarn binders were oriented along the warp direction.

The evolution of the stiffness as a function of the applied strain was obtained from the tests in which the coupon was periodically unloaded and reloaded. It is plotted in Fig. $4 \mathrm{a}$ and b for the coupons deformed in the fill and warp directions, respectively. The stiffness was obtained from the slope of the stress-strain curve at the beginning of the unloading cycle, from the initial unloading point up to the point at which the load has decreased by $20 \%$. The residual strain (understood as the longitudinal strain at zero load at the end of the unloading part of the cycle) is also plotted in these figures. In the case of the coupons deformed in the fill direction (Fig. 4a), the stiffness remained constant (or even increased slightly) up to the onset of carbon fiber failure (1.3-1.4\%), even though the continuous increment of the residual strain in this range indicated the development of irreversible damage mechanisms in this region. It should be noted that the PE z-yarn oriented in the warp direction induced fiber crimping in the fill tows and the straightening of the carbon and glass fiber tows upon deformation could compensate the reduction in stiffness due to damage, leading to this plateau in the longitudinal stiffness. Fracture of the carbon fiber yarns led to a dramatic reduction in stiffness prior to failure while the permanent strain increased accordingly. In the coupons oriented along the warp direction (Fig, 4b), stiffening of the coupon due to the straightening of glass and carbon fiber yarns was not significant and a continuous reduction in stiffness was observed from the beginning of the test, together with an increase in the residual strain. Both (reduction in stiffness and increase in residual strain) were enhanced after fracture of the carbon fiber tows.

\subsection{Tensile properties of open-hole coupons}

The tensile stress-strain curves of the open-hole tests are plotted in Fig. $5 \mathrm{a}$ and b for coupons with a central hole of $4.1 \mathrm{~mm}$ and $11 \mathrm{~mm}$ in diameter, respectively. These curves present similarities and differences with those measured in plain coupons (Fig. 3). The maximum strength was also attained at lower strains when the composite was loaded in the fill direction and was dictated by the fracture of the carbon fibers. The coupons loaded in the warp direction attained the maximum strength at higher strains after the failure of carbon fibers. Nevertheless, damage in the ligament induced by the presence of the hole leads to a non-linear

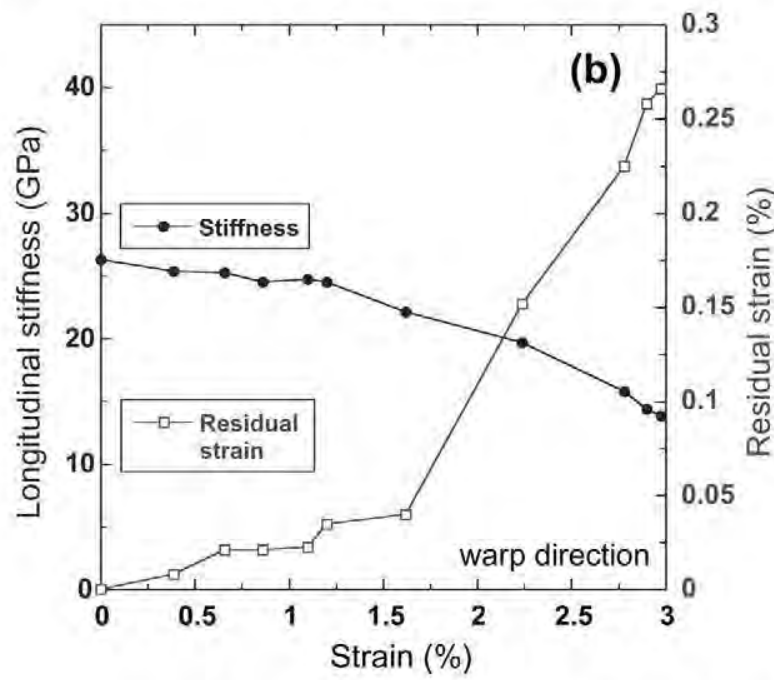

stress-strain curve even in the samples loaded in the fill direction. The non-linearity increased with the hole diameter. Moreover, the specimen failure after the peak strength was gradual, particularly in the specimens with large holes (Fig. 5b). This behavior is indicative of a ductile failure mechanism in which the material in the ligament failed progressively as the applied strain increased.

The notch sensitivity of the hybrid 3D woven composite in the fill and warp directions is shown in Fig. $5 c$, in which the failure stress (normalized by the average failure stress of the plain coupon) is plotted as a function of the hole diameter (divided by the coupon width). The experimental results for the open hole tests with different hole diameter are very close to the straight line which indicates that failure strength was proportional to the ligament width (particularly in the fill direction) and thus that the stress concentration induced by the circular hole did not influence the failure strength. Reduced notch sensitivity in carbon/epoxy 3D woven composites was already reported $[8,9]$ and it was partly attributed to the presence of geometrical flaws that were broadly distributed in strength and space; and partly to the coarseness of the reinforcing yarns, which led to extensive debonding and reduced stress intensification around sites of failure. Nevertheless, the hybrid 3D woven composites presented better notch insensitivity, indicating that hybridization with glass and PE fibers improves the damage tolerance.

\section{Damage and failure micromechanisms}

\subsection{Loading along the fill direction}

XCT provides unique information regarding the microscopic damage and failure micromechanisms which develop during deformation of the complex 3D microstructure of the hybrid composite material. XCT was carried out in one coupon deformed in the fill direction and deformed up to strains of $1.05 \%$ and $1.74 \%$ (marked with solid circles in Fig. 3a). The first analysis occurred in the linear region of the stress-strain curve, before carbon fiber breakage took place. Two cross-sections of the investigated volume parallel to the loading axis are shown in Fig. $6 \mathrm{a}$ and $\mathrm{b}$. In all the cross-sections below, glass fiber yarns appear light gray, carbon, PE fiber yarns and matrix appear dark gray and white regions correspond to cracks or voids infiltrated by $\mathrm{ZnI}$. The two sections in Fig. 6 are parallel and one of them (Fig. 6b) contains the PE z-yarns, which run in the vertical direction. The two carbon layers running in the fill and warp directions are at the top in Fig. 6. and the missing yarn every other

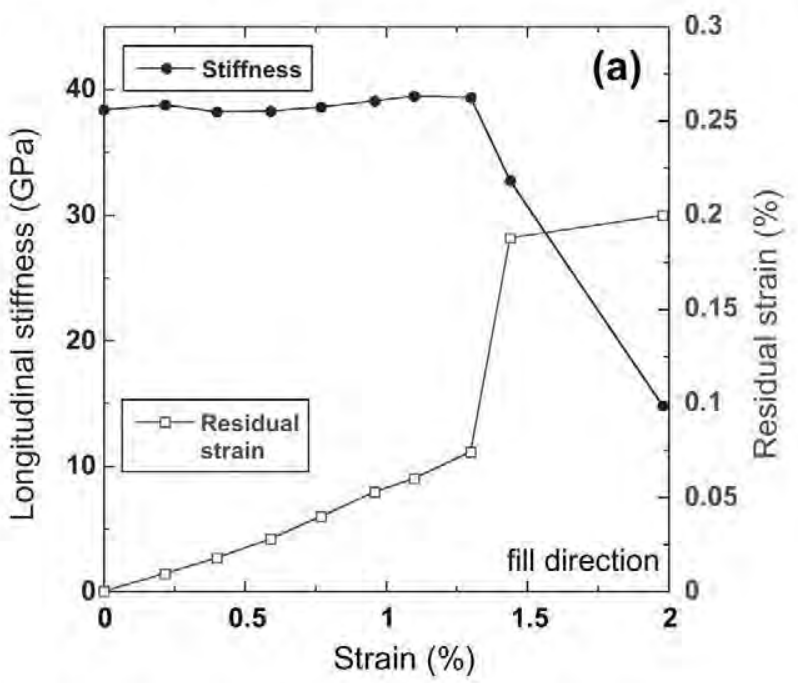

Fig. 4. Evolution of the elastic modulus and of the residual strain (at zero load) with the applied strain. (a) Fill direction. (b) Warp direction. (For interpretation of the references to colour in this figure legend, the reader is referred to the web version of this article.) 

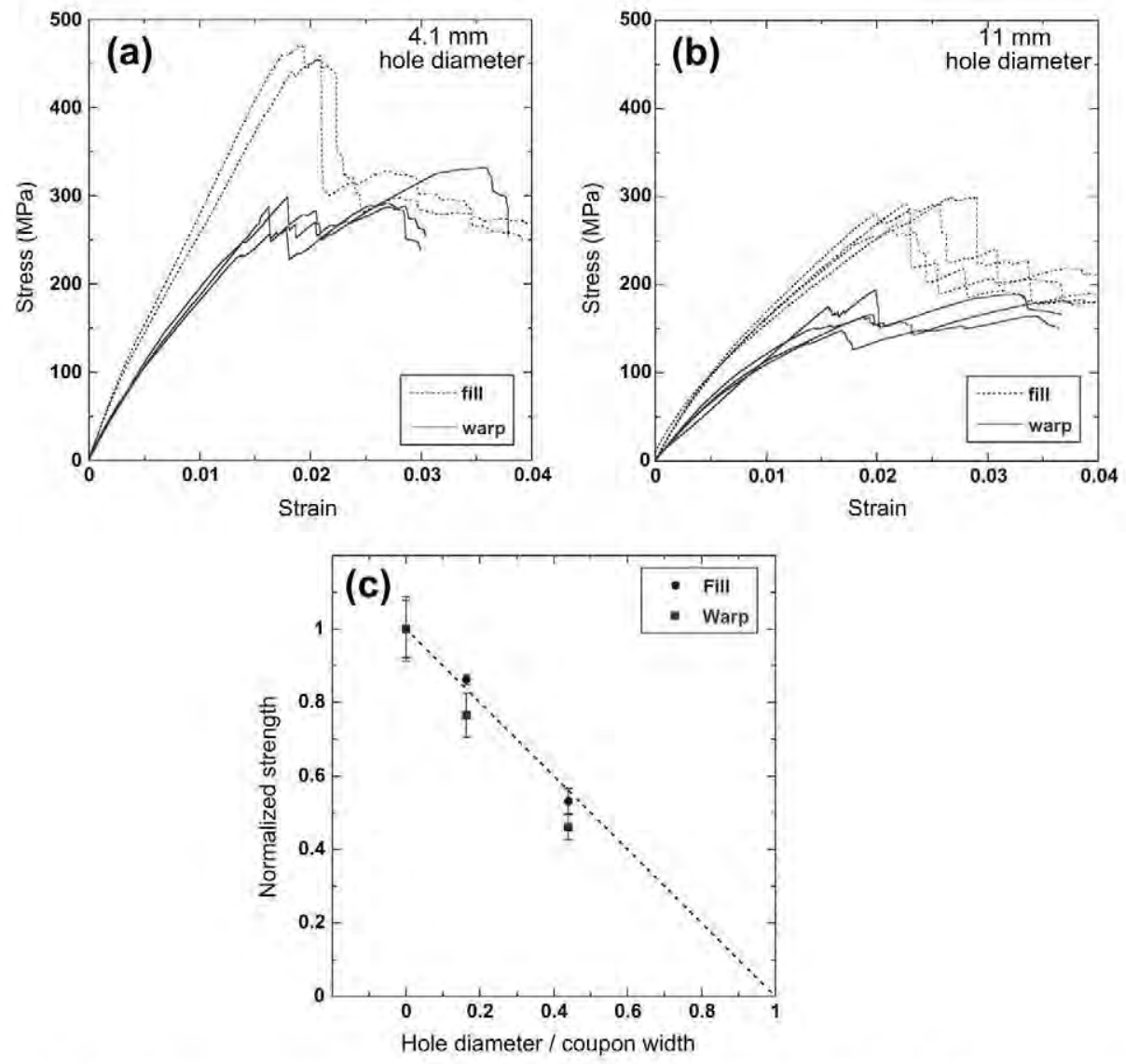

Fig. 5. Stress-strain curves of the open-hole composite coupons in the fill and warp direction. (a) Hole diameter of $4.1 \mathrm{~mm}$. (b) Hole diameter of $11 \mathrm{~mm}$. (c) Notch sensitivity of the 3D hybrid woven composite. The notch insensitive behavior is given by the dashed straight line. (For interpretation of the references to colour in this figure legend, the reader is referred to the web version of this article.)

yarn in the warp direction is clearly visible in Fig. 6a. The four glass fiber layers are at the bottom and the hybrid layer (light gray/dark gray contrast) is in between. The resin-rich area due to the missing yarn enhanced crimping of the adjacent carbon and carbon/glass yarns in the fill directions, leading to delamination of the fill tows from the matrix (marked with arrows). These delamination cracks propagated along the tows and notice that delamination was asymmetric: only the upper or the lower tow boundary was delaminated from the matrix. In addition, tensile transverse cracks were observed in the fiber tows oriented in the warp direction (perpendicular to the tensile loading). These cracks propagated through the matrix (and along the interface) within the fiber tows. The parallel cross-section in Fig. 6b depicted the same failure mechanisms (namely, delamination of the carbon and hybrid fill tows from the matrix near the missing warp tows and tensile cracking of the warp tows). It is worth noting that the PE z-yarns arrested the propagation of the delamination cracks because the PE z-yarns will lead to through-thickness compression of the laminate as it stretches along the the fill direction. In addition, delamination of PE z-yarns was also evident (marked with arrows).

More information about the damage mechanisms was obtained from the cross-sections perpendicular to the loading axis, which are shown in Fig. 7. The delamination cracks at the boundary of the carbon and glass fiber tows (already shown in Fig. 6) are also visible in this section, together with delamination cracks at the boundary of PE z-yarns (Fig, 7). The delamination cracks were also arrested by the PE z-yarns. In addition, cracking within the fiber tows parallel to the loading axis (marked with arrows) was found. Their number was higher in the fiber tows surrounded by the PE zyarns (Fig. 7), in which cracks oriented in the horizontal and vertical direction are seen. The cracks parallel to the loading axis within the fiber tows could not be attributed to the far-field tensile stress field and were due to the longitudinal shear stresses that develop within the tow as a result of asymmetric tow delamination from the matrix, i.e. the upper boundary of the tow delaminates from the matrix and deforms along the loading direction while the lower boundary remains adhered to the matrix (or viceversa).

The second XCT inspection of the specimen loaded in the fill direction was carried out at $1.74 \%$ strain after fracture of the carbon fiber tows. The tomograms in the longitudinal sections parallel to the loading axis are shown in Fig. 8. Fracture of the carbon fiber tows is clearly visible in the upper region of the specimen as well as extensive delamination of the fiber tows from the matrix (Fig. 8a). In addition, delamination cracks propagated from one layer to another through the warp tows. The parallel section containing the PE z-yarns (Fig. 8b) shows that they were able to arrest the longitudinal delamination cracks. In addition to these failure mechanisms, tensile cracks within the warp were found in both longitudinal sections. The inspection of the composite sections perpendicular to the loading axis (Fig. 9) showed that fracture of the carbon tows has enhanced the development of the delamination cracks at the boundary of all the fiber tows (carbon, glass and $\mathrm{PE}$ ). As a result, the number of shear cracks parallel to the loading axis have also increased and multiple shear cracks were visible within many glass fiber tows (Fig. 9).

\subsection{Loading along the warp direction}

XCT was carried out in one coupon deformed in the warp direction at strains of $1.19 \%$ and $2.15 \%$ (marked with solid circles in 

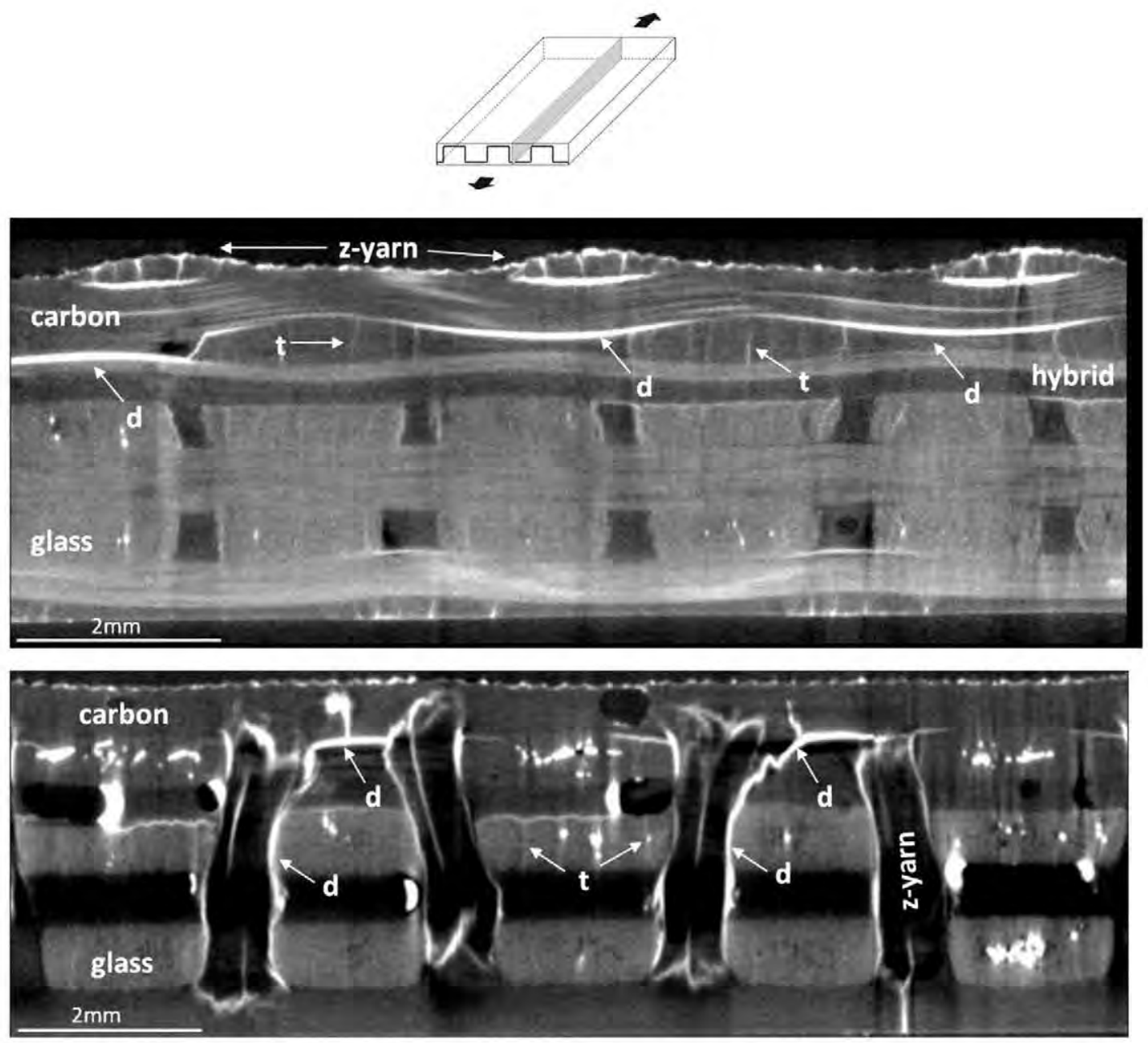

Fig. 6. Tomograms of the coupon loaded in the fill direction up to $1.05 \%$ strain (a) longitudinal section parallel to the (horizontal) loading axis, and (b) another longitudinal section parallel to the (horizontal) loading axis which contains the PE z-yarns. Arrows indicate the different damage mechanisms: $\mathbf{d}$ stands for delamination cracks from the fiber tows and $\mathrm{z}$-yarns and $\mathbf{t}$ indicates transverse tensile cracks within the fiber tows.

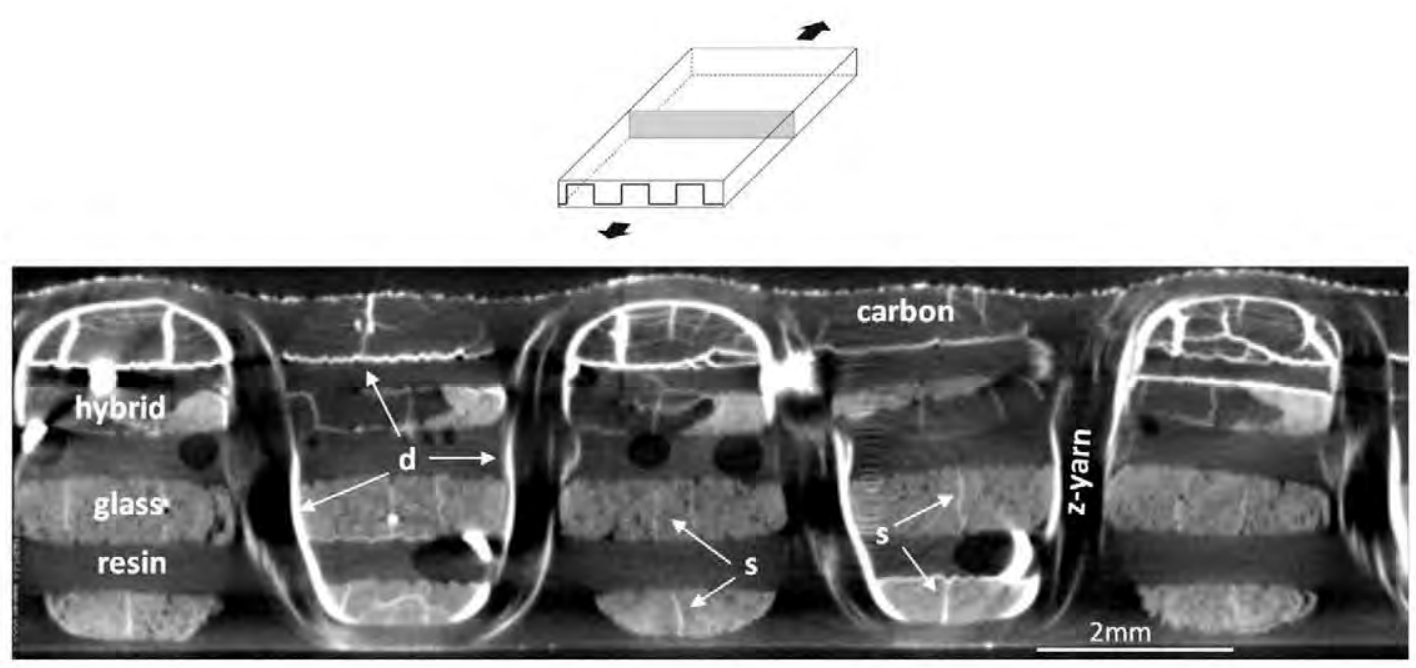

Fig. 7. Tomograms of the coupon loaded in the fill direction up to $1.05 \%$ strain. Transverse section perpendicular to the loading axis. Arrows indicate the different damage mechanisms: $\mathbf{d}$ stands for delamination cracks from the fiber tows and $z$-yarns and $\mathbf{s}$ indicates shear cracks within the fiber tows.

Fig. 3b). The tomograms of cross-sections parallel and perpendicular to the loading axis deformed up to $1.19 \%$ are depicted in Figs. 10 and 11 , respectively. The main damage mechanisms observed in the longitudinal sections which did not contain PE z-yarns were fiber tow delamination and tensile transverse cracks within the fiber tows (Fig. 10a). Delamination cracks were occasionally deflected into the fiber tows, propagated across the tow and led to another delamination crack at the opposite tow surface. The 

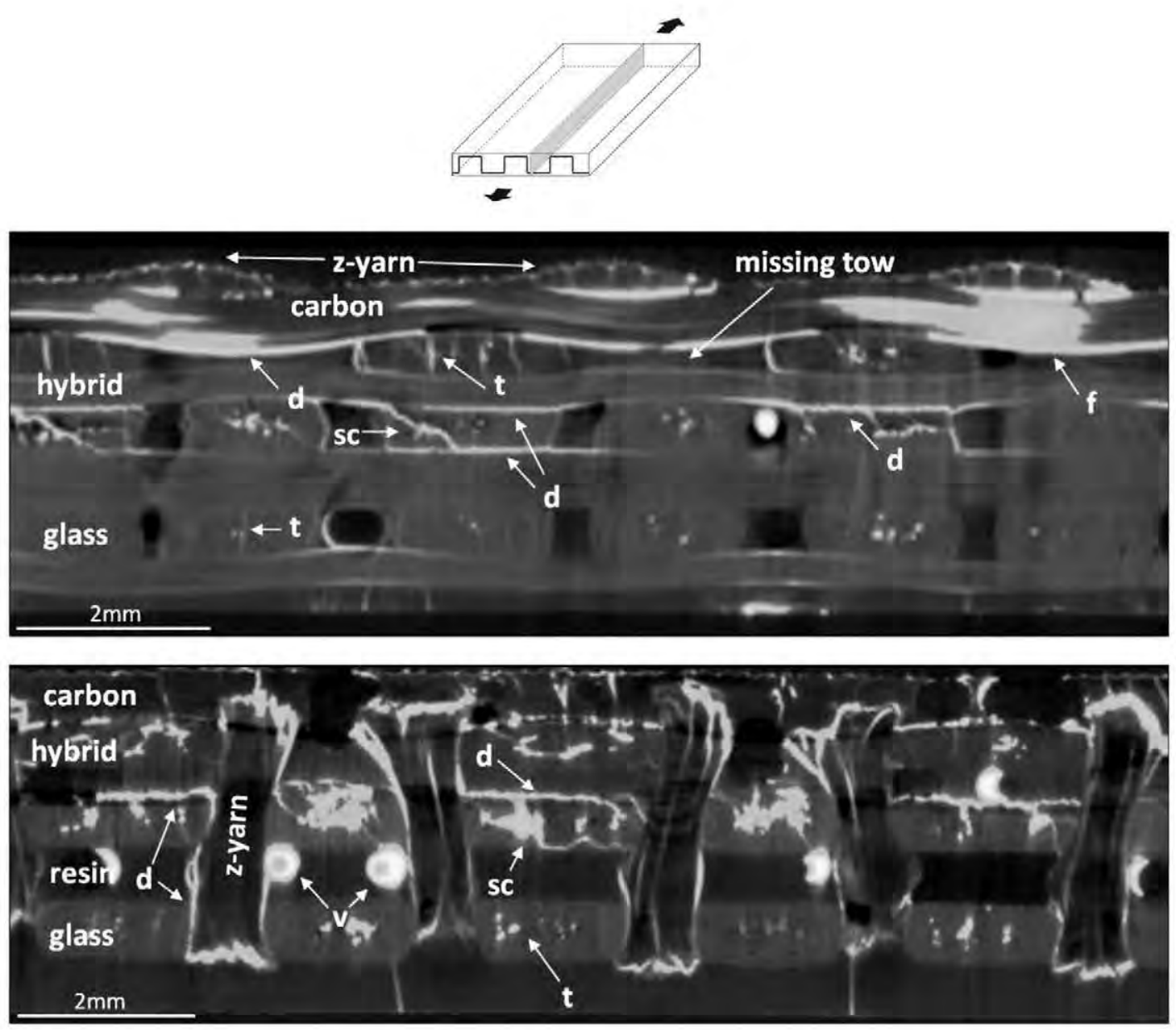

Fig. 8. Tomograms of the coupon loaded in the fill direction up to $1.74 \%$ strain. (a) Longitudinal section parallel to the (horizontal) loading axis, and (b) another longitudinal section parallel to the (horizontal) loading axis which contains the PE z-yarns. Arrows indicate the different damage mechanisms: $\mathbf{f}$ stands for the fracture of the carbon fiber tows, $\mathbf{t}$ tensile transverse cracks within the fiber tows, $\mathbf{d}$ delamination of the fiber tows, sc slanted translaminar cracks within the fiber tows created by propagation of delamination cracks through the tow and $\mathbf{v}$ voids.
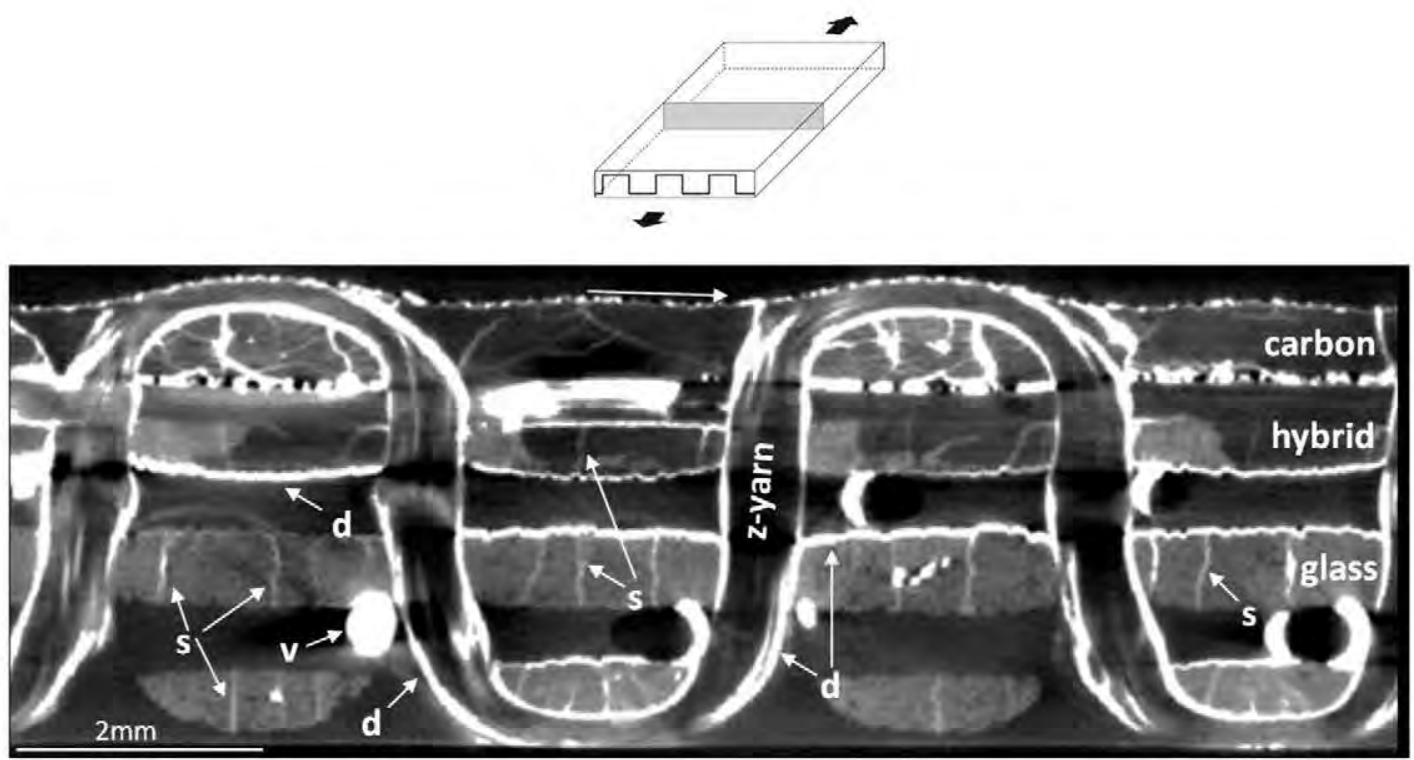

Fig. 9. Tomograms of the coupon loaded in the fill direction up to $1.74 \%$ strain. Transverse section perpendicular to the loading axis. Arrows indicate the different damage mechanisms: $\mathbf{t}$ tensile cracks within the fiber tows, $\mathbf{d}$ delamination of the fiber tows, $\mathbf{s}$ indicates shear cracks within the fiber tows, and $\mathbf{v}$ voids.

sections containing PE z-yarns also showed extensive delamination of the PE yarns from the matrix and carbon and glass fiber tows, while delamination cracks between matrix and carbon or glass were arrested by the z-yarns (Fig. 10b). 

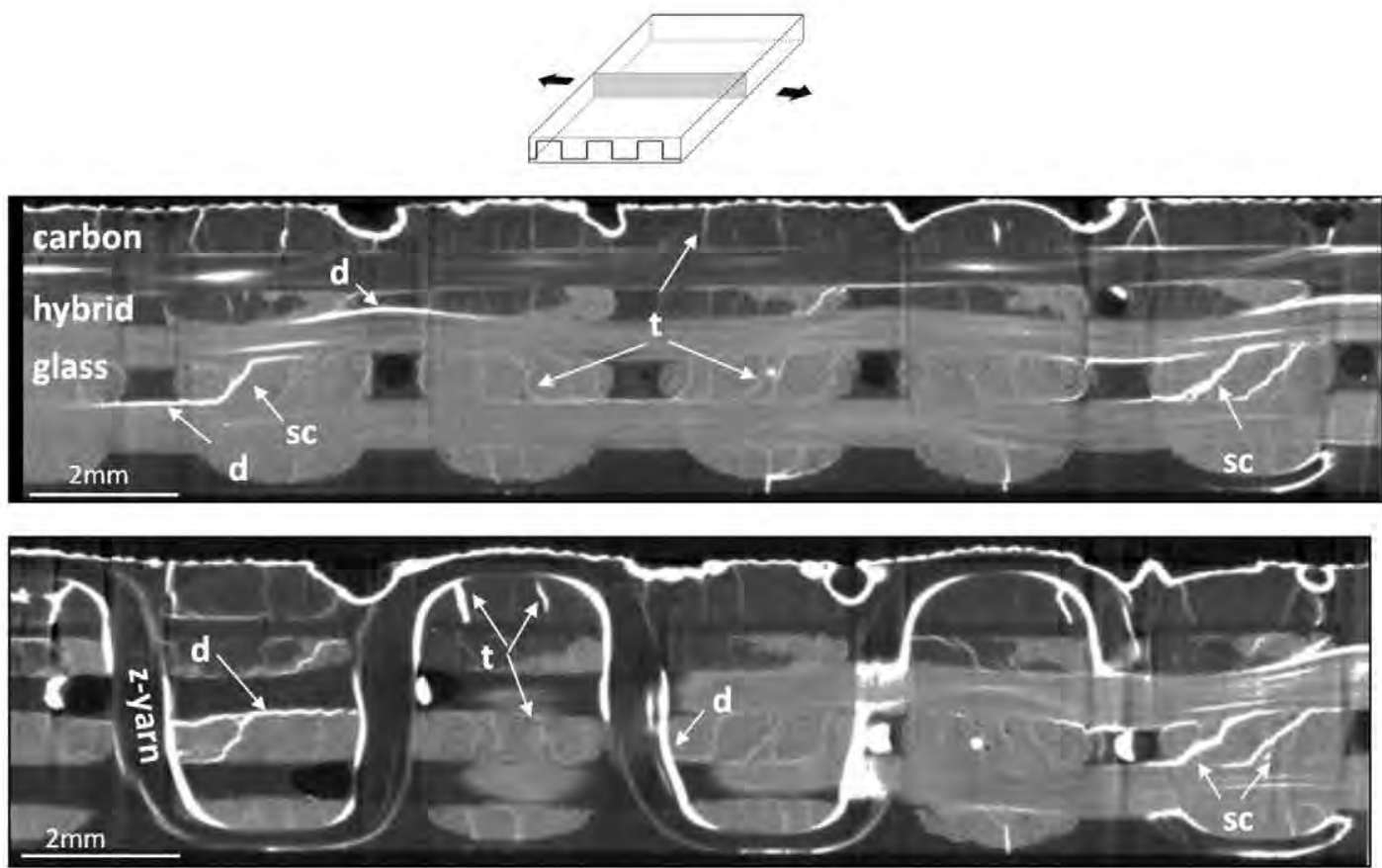

Fig. 10. Tomograms of the coupon loaded in the warp direction up to $1.19 \%$ strain. (a) Longitudinal section parallel to the (horizontal) loading axis, and (b) another longitudinal section parallel to the (horizontal) loading axis which contains the PE $\mathbf{z}$-yarns. Arrows indicate the different damage mechanisms: $\mathbf{t}$ tensile transverse cracks within the fiber tows, d delamination of the fiber tows, sc slanted translaminar cracks within the fiber tows created by propagation of delamination cracks through the tow.
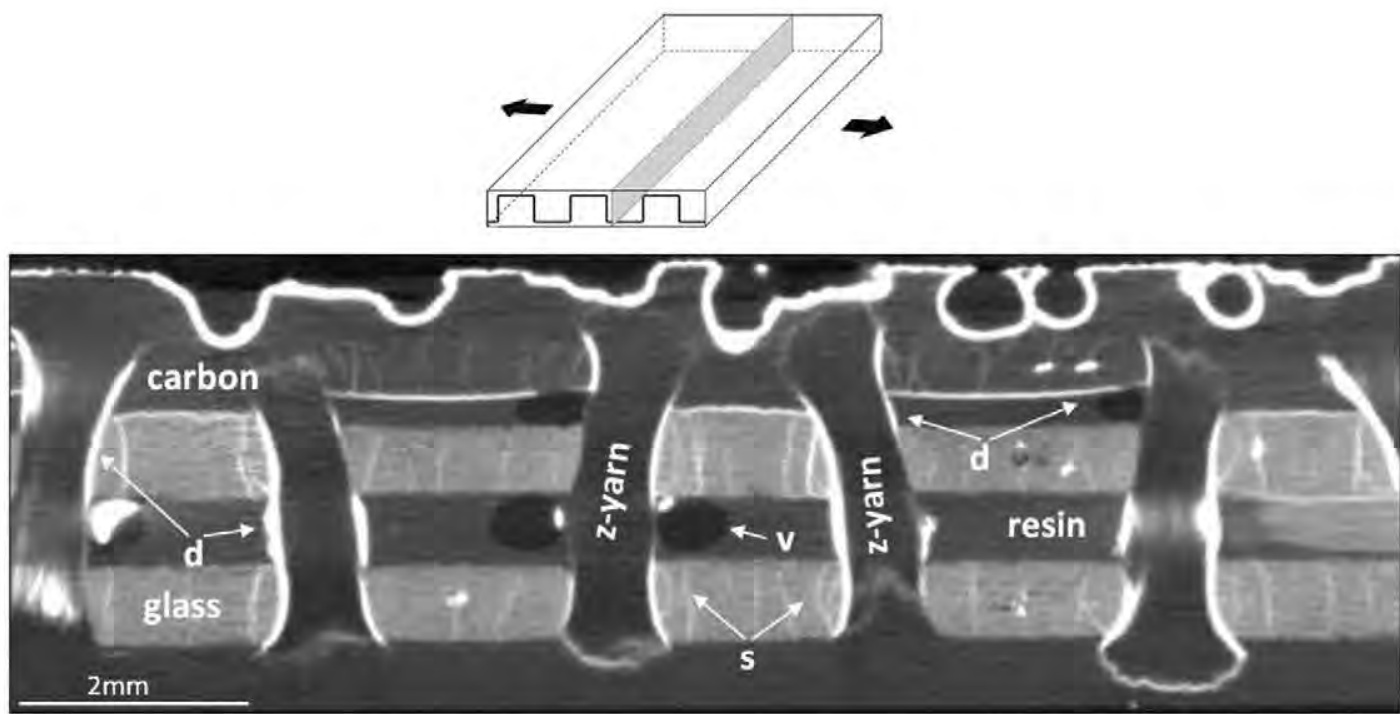

Fig. 11. Tomograms of the coupon loaded in the warp direction up to $1.19 \%$ strain. Transverse section perpendicular to the loading axis. Arrows indicate the different damage mechanisms: $\mathbf{s}$ shear cracks within the fiber tows, $\mathbf{d}$ delamination of the fiber tows, and $\mathbf{v}$ indicated voids (which appear black).

The XCT of the sections perpendicular to the loading axis at $1.19 \%$ strain (Fig. 11) showed the expected damage mechanisms: delamination cracks between the matrix and the fiber tows (PE, carbon and glass) as well as extensive shear cracks within the carbon and glass fiber tows induced by the asymmetric delamination of the fiber tows from the matrix.

XCT in the composite coupons loaded in the warp direction after the fracture of the carbon yarns are depicted in Figs. 12 and 13. Fig. 12 includes the cross-sections parallel to the loading axis, in which extensive tensile transverse cracks in the carbon tows appear as the main damage mechanism (Fig. 12a). Delamination cracks at the fiber tow interfaces are visible but preferentially at the PE z-yarn boundaries (Fig. 12b). They propagated into the carbon and glass fiber tows, leading to extensive intratow cracking. The cross sections perpendicular to the loading axis showed extensive damage in the carbon fiber tows (Fig. 13), while shear cracking of the glass and hybrid fiber tows was visible throughout the section. Maximum shear crack density within the tows was found on the sections containing the PE z-yarns (Fig. 13) and it was triggered by the shear stresses within the tow promoted by the delamination of the z-yarns.

\section{Prediction of the coupon properties}

Although XCT analyses showed the development of different damage mechanisms upon tensile deformation, the tensile 

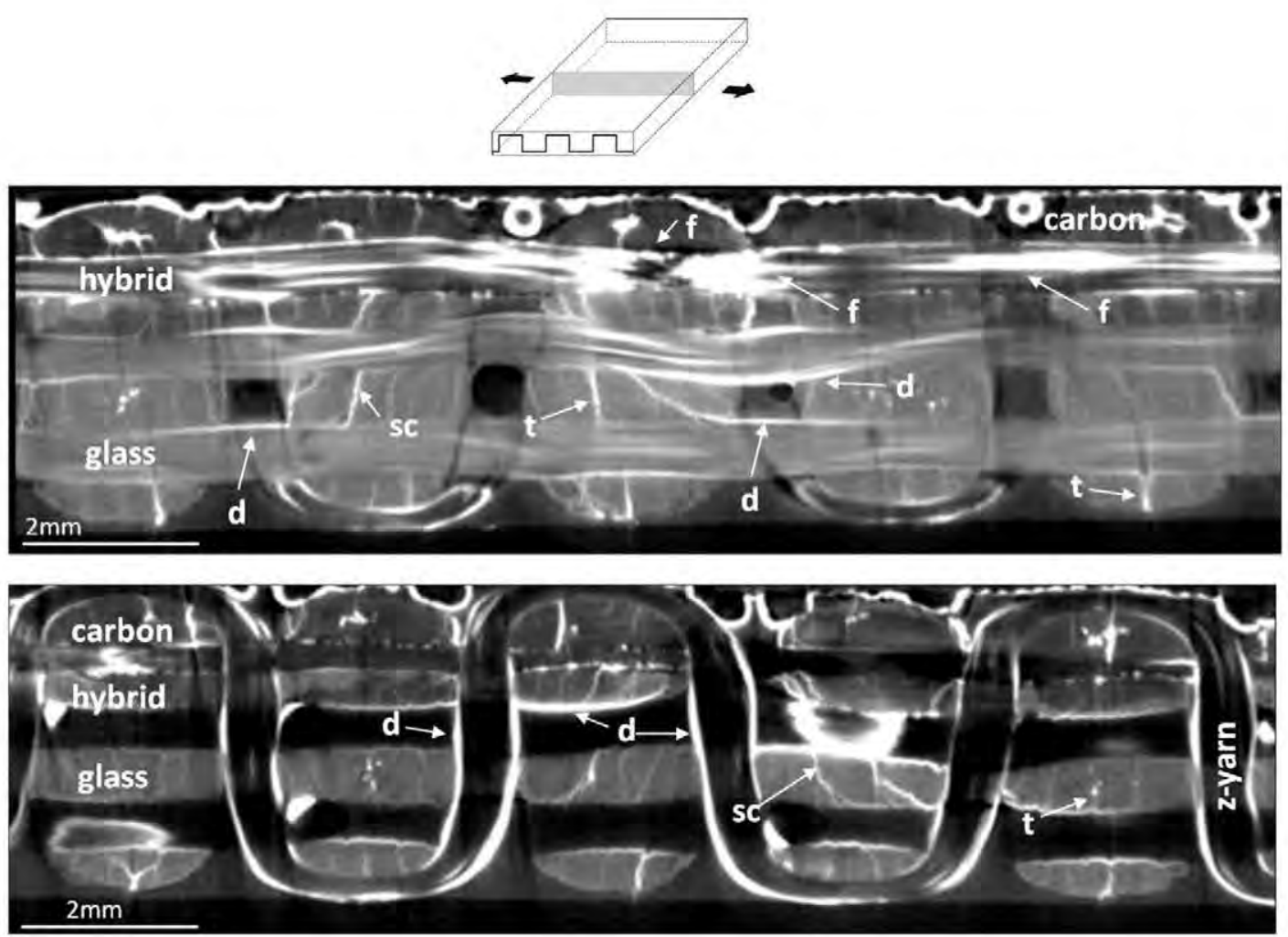

Fig. 12. Tomograms of the coupon loaded in the warp direction up to $2.15 \%$ strain. (a) Longitudinal section parallel to the (horizontal) loading axis, and (b) another longitudinal section parallel to the (horizontal) loading axis which contains the PE z-yarns. Arrows indicate the different damage mechanisms: $\mathbf{f}$ stands for the fracture of the carbon fiber tows, $\mathbf{t}$ tensile transverse cracks within the fiber tows, $\mathbf{d}$ delamination of the fiber tows, sc slanted translaminar cracks within the fiber tows created by propagation of delamination cracks through the tow.
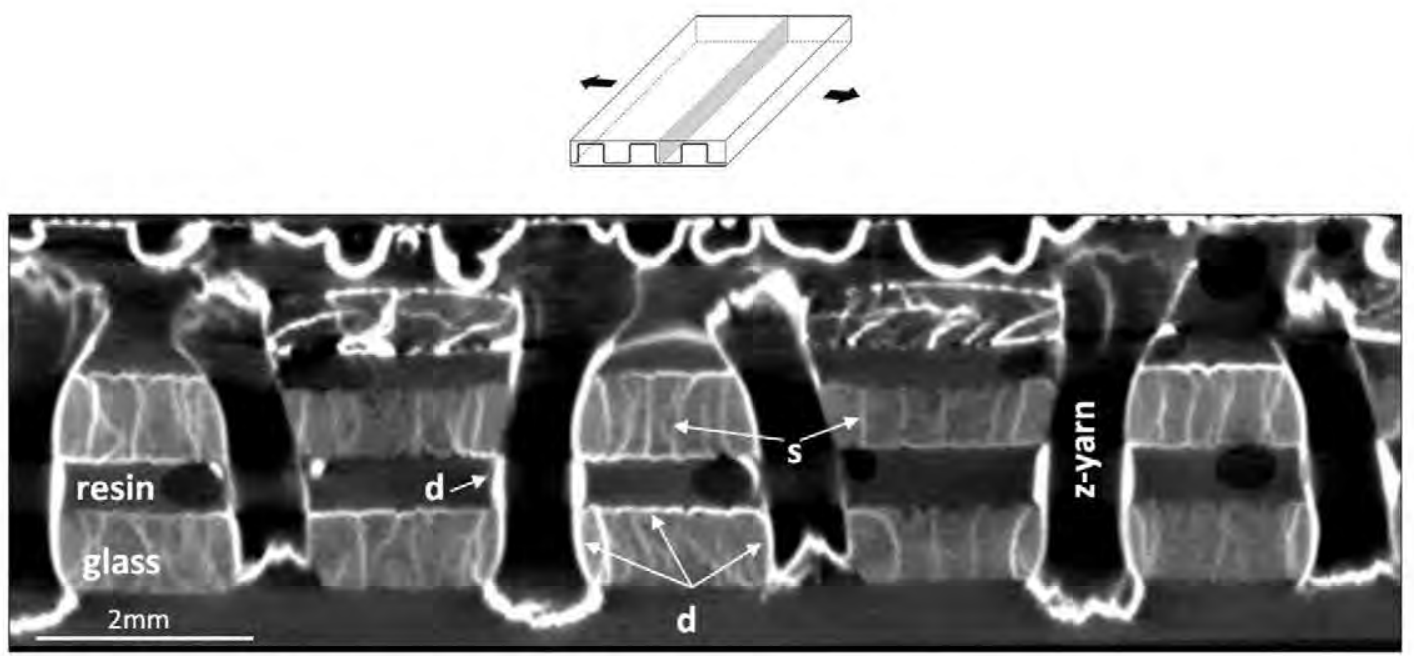

Fig. 13. Tomograms of the coupon loaded in the warp direction up to $2.15 \%$ strain. Transverse section perpendicular to the loading axis. Arrows indicate the different damage mechanisms: $\mathbf{f}$ stands for the fracture of the carbon fiber tows, $\mathbf{s}$ shear cracks within the fiber tows, and $\mathbf{d}$ delamination of the fiber tows.

strength of the composite coupons seemed to be controlled by the fracture of the fiber yarns in the loading direction. Previous investigations of the tensile behavior of 3D woven composites [8] have shown that the tensile strength can be estimated fairly well from the stress carried by the individual tows oriented in the loading direction assuming an isostrain approach. According to this hypothesis, the composite mechanical behavior in the fill and warp directions should be predicted from the experimental values of the fiber elastic modulus and failure strain obtained from the fiber tow tests using a simple model based on the rule of mixtures. The composite elastic modulus in the fill $\left(E^{f}\right)$ and warp $\left(E^{w}\right)$ directions could be expressed as

$$
\begin{aligned}
& E^{f}=E_{c} f_{c}^{f}+E_{s 2} f_{s 2}^{f}+E_{m}\left(1-f_{c}^{f}-f_{s 2}^{f}\right) \\
& E^{w}=E_{c} f_{c}^{w}+E_{s 2} f_{s 2}^{w}+E_{p e} f_{p e}^{w} / 2+E_{m}\left(1-f_{c}^{w}-f_{s 2}^{w}-f_{p e}^{w} / 2\right)
\end{aligned}
$$


Experimental results and model predictions for the elastic modulus and tensile strength of the 3D hybrid woven composite in the fill and warp directions.

\begin{tabular}{llll}
\hline \multirow{2}{*}{ Orientation } & Elastic modulus & & Tensile strength \\
\cline { 2 - 3 } & Experiments $(\mathrm{GPa})$ & Model $(\mathrm{GPa})$ & Experiments $(\mathrm{MPa})$ \\
\hline Fill & $38.4 \pm 1.6$ & 38 & $531 \pm 42$ \\
Warp & $24.6 \pm 0.7$ & 24.6 & $395 \pm 35$ \\
\hline
\end{tabular}

where $E_{c}, E_{s 2}$ and $E_{p e}$ stand for the elastic moduli of the fibers (Table 2), $f_{c}^{f}, f_{52}^{f}$ are the carbon and glass fiber volume fractions in the fill direction (Table 1 ), and $f_{c}^{w}, f_{s 2}^{w}$ and $f_{p e}^{w}$ the carbon, glass and PE fiber volume fractions in the warp direction (Table 1), respectively. This model assumes that the contribution to the elastic modulus of the fiber yarns perpendicular to either the fill or the warp direction is given by the matrix modulus, $E_{m}$, which was taken as 2.9 GPa, according to the manufacturer. In addition, only one half of the volume fraction of the PE fibers was considered to compute the elastic modulus in the warp direction because of the shape of the PE z-yarns. The model predictions are compared with the experimental data in Table 3 , showing excellent agreement and supporting the use of the isostrain approach to model the elastic deformation in tension of hybrid 3D woven composites.

The prediction of the tensile strength in the fill direction, $X^{f}$, was carried out using the same model under the assumption that the composite behavior is linear until fracture. Thus,

$X^{f}=E^{f} \epsilon_{c}$

where $\epsilon_{c}$ is the failure strain of the carbon fiber tows (Table 2). In the case of the warp direction, the tensile strength was attained at the fracture of the glass fibers after the carbon fiber yarns were broken. Neglecting the contribution of the carbon fiber yarns to the elastic modulus, the composite tensile strength in the warp direction, $X^{w}$ can be computed as

$X^{w}=\left[E_{s 2} f_{s 2}^{w}+E_{p e} f_{p e}^{w} / 2+E_{m}\left(1-f_{c}^{w}-f_{s 2}^{w}-f_{p e}^{w} / 2\right)\right] \epsilon_{s 2}$

where $\epsilon_{s 2}$ stands for the fracture strain of the glass fiber tows. The model predictions are compared with the experimental results in Table 3. The model predictions in the fill direction are very accurate, as this is the result of the linear behavior of the composite until the fracture of the carbon fiber tows (Fig. 3a). However, the model overestimated the composite strength in the warp direction because the failure strain of the composite $(2.8 \% \pm 0.3 \%)$ was much lower than the failure strain of the glass fiber bundles $(4.0 \% \pm 1 \%)$, which controlled the composite strength in this orientation. In fact, if the failure strain of the S2 glass fiber yarns, $\epsilon_{s 2}$ in Eq. (4) is substituted by the failure strain the coupon in the warp direction $(2.8 \%)$, the isostrain model prediction for the composite strength in the warp direction drops to $428 \mathrm{MPa}$, close to the experimental results. The early fracture of the glass fiber bundles was very probably promoted by the bending stresses induced in the asymmetric hybrid laminate after the failure of the carbon fibers and the stress concentration in the vicinity of failed tows. These mechanisms limited the maximum loading bearing capability of the hybrid composite.

\section{Concluding remarks}

The analysis of the deformation and failure micromechanisms of a hybrid 3D woven composite in tension showed that the elastic deformation was controlled by the elastic modulus and volume fraction of fiber yarns oriented in the loading direction. Due to the complex 3D architecture, damage developed at low strains in the form of debonding of the fiber tows (longitudinal and z-yarns) as well as of tensile and shear cracking of the fiber tows. Tow debonding was arrested by the z-yarns whereas tensile transverse cracks were concentrated within fiber tows perpendicular to the loading axis. Shear cracking of the fiber tows was due to asymmetric debonding of the fiber tows from the surrounding material and developed in longitudinal and transversal tows. Nevertheless, the influence of these damage mechanisms in the elastic modulus was limited and, depending on the architecture, was balanced by the straightening of the fiber tows upon tensile straining. Thus, the elastic moduli in both fill and warp directions was accurately predicted by an isostrain model using the actual properties of the fiber tows within the composite.

Elastic deformation stopped abruptly when the applied strain reached $\approx 1.5 \%$ due to the brittle failure of the carbon fiber tows. This first peak in the stress-strain curve could be adequately predicted by the isostrain model and bending stresses (induced by the non-symmetric laminate) did not influence the mechanical response. Nevertheless, fracture of the carbon yarns did not lead to the laminate fracture because the laminate was held together by the PE z-yarns while the glass fiber tows continued supporting the applied load. This led to another peak in the stress-strain curve, which was controlled by the fracture of the glass fiber tows. Whether or not the second peak was higher than the first one depended on the volume fraction of carbon and glass fibers oriented in the loading direction. It should be noted that the strain at which this second peak was attained (2-3\%) was significantly lower than the failure strain of the glass fiber tows $(\approx 4 \%)$. This is likely due to the combining effect of two factors: the development of bending stresses in the damaged coupon and the stress concentration in the vicinity of failed tows. It is also worth noting that the PE zyarns will lead to through-thickness compression of the laminate as it stretches along the the warp direction. This will enhance friction between warp tows, improving the shear load transfer between tows and increasing the probability that significant loads can be sustained by the warp tows even after some of them (primarily carbon, but increasingly glass too as the strain increases) have failed. This enhanced friction is a major potential source of damage tolerance and energy absorption [23]. Thus, the full contribution of the glass fibers to the composite strength was not employed but their presence increased the fracture strain and the energy dissipated during fracture. Thus, hybridization of the 3D woven composite led to a notch-insensitive behavior as demonstrated by open-hole tests.

This preliminary investigation points out the complexity of the deformation and damage mechanisms in hybrid 3D woven composites and further detailed analyses are required to understand the interaction among the different processes. This information will be critical to establishing design rules to optimize the behavior of these composites under different loading conditions, taking advantage of the different stiffness and failure strains of the fibers in the composite and of the asymmetry in the laminate.

\section{Acknowledgements}

This investigation was supported by the Spanish Ministry of Economy and Competitiveness through the project MUDATCOM (MAT2012-37552) and by the Comunidad de Madrid through the program ESTRUMAT-CM (S2009/MAT-1585). The authors acknowledge 3TEX Inc. for providing the material and the areal densities. 
The help of Mr. J.C. Rubalcaba, Mr. J.L. Jimenez and Ms. E. Moreno is also gratefully acknowledged.

\section{References}

[1] Aveston J, Kelly A. Tensile first cracking strain and strength of hybrid composites and laminates. Philos. Trans. Roy. Soc. Lond. A 1980:294:519-34.

[2] Hanomsilp C, Hogg PJ. Penetration impact resistance of hybrid composites based on commingled yarn fabrics. Compos. Sci. Technol, 2003;63:467-82.

[3] Naik NK, Ramsimha R, Arya H, Prabhu SV, Shamarao N. Impact response and damage tolerance characteristics of glass-carbon/epoxy hybrid composite plates. Composites: Part B 2001;32:565-74.

[4] Hosur MV, Adbulah M, Jeelani S. Studies of the low-velocity impact response of woven hybrid composites, Compos. Struct, 2005;67:253-62.

[5] Sevkat E, Liaw B, Delate F, Raju BB. Drop-weight impact of plain woven hybrid glass-graphite/toughened epoxy composites. Composites: Part A 2009:40: 1090-100.

[6] Enfedaque A, Molina-Aldareguía JM, Gálvez F, González C, LLorca ]. Effect of glass-fiber hybridization on the behavior under impact of woven carbon fiber/ epoxy laminates. J. Compos. Mater. 2010;44:3051-68.

[7] Chen F, Hodgkinson JM. Impact behaviour of composites with different fibre architecture. J. Aerosp. Eng. 2009;223:1009-17.

[8] Cox BN, Dadkhah MS, Morris WL, Flintoff JG. Failure mechanisms of 3D woven composites in tension, compression and bending. Acta Metall. Mater. 1994;42: 3967-84.

[9] Cox BN, Dadkhah MS, Morris WL. On the tensile failure of 3D woven composites. Composites: Part A 1996:27A:447-58.

[10] Gerlach R, Siviour RC, Wiegand J, Petrinic N. In-plane and through-thickness properties, failure modes, damage and delamination in $3 \mathrm{~d}$ woven carbon fibre composites subjected to impact loading. Compos. Sci. Technol. 2012;72: 397-411.

[11] Bogdanovich AE, Karahan M, Lomov SV, Verpoest 1. Quasi-static tensile behavior and damage of carbon/epoxy composite reinforced with 3D noncrimp orthogonal woven fabric. Compos. Sci. Technol. 2013;62:14-31.
[12] Ivanov DS, Lomov SV, Bogdanovich $\Lambda$ E, Karahan M, Verpoest I. A comparative study of tensile properties of non-crimp $3 \mathrm{~d}$ orthogonal weave and multi-layer plain weave e-glass composites. Part 2: comprehensive experimental results. Composites: Part A 2009;40:1144-57.

[13] Pankow M, Waas A, Yen C, Ghiorse S. Resistance to delamination of 3D woven textile composites evaluated using end notch flexure tests: experimental results. Composites: Part A 2011:42:1463-76.

[14] Seltzer R, González C, Muñoz R, Llorca J, Blanco-Varela T. X-ray microtomography analysis of the damage micromechanisms in $3 \mathrm{D}$ woven composites under low-velocity impact. Composites: Part A 2013;45:49-60.

[15] Pankow M, Yen Chian-fong, Rudolph M, Justusson B, Zhang D, Waas A. Experimental investigation on the deformation response of hybrid $3 D$ woven composites. In: 53rd AIAA/ASME/ASCE/AHS/ASC structures, structural dynamics and materials conference; 2012 [10.2514/6.2012-1572].

[16] ASTM, D3039 Standard test method for tensile properties of polymer matrix composite materials.

[17] ASTM, D5766 Standard test method for open-hole tensile strength of polymer matrix composite laminates.

[18] ASTM, D4018 Standard test methods for properties of continuous filament carbon and graphite fiber tows.

[19] Sket F, Enfedaque A, Alton C, González C, Molina-Aldareguîa JM, LLorca J. Automatic quantification of matrix cracking and fiber rotation by $X$-ray computed tomography during shear deformation of carbon fiber-reinforced laminates. Compos. Sci. Technol. 2014;90:129-38.

[20] Stock SR. X-ray microtomography of materials. Int. Mater. Rev. 1999:44: 141-64.

[21] Breunig TM, Stock SR, Guvenilir A, Elliot JC, Anderson P, Davis GR. Damage in aligned-fibre SiC/Al quantified using a laboratory X-ray tomographic microscope. Composites 1993;24:209-13.

[22] Schilling PJ, Karedla BR, Tatiparthi AK, Verges MA, Herringtón PD, X-ray computed microtomography of internal damage in fiber reinforced polymer matrix composites, Compos, Sci. Technol. 2005:65:2071-8.

[23] McGlockton MA, Cox BN, McMeeking RM. A binary model of textile composites: III high failure strain and work of fracture in $3 \mathrm{D}$ weaves. I. Mech. Phys. Solids 2003:51:1573-600. 